Received: 01.10 .2018

Revised: 27.11 .2018

Accepted: 30.11 .2018

DOI: $10.17804 / 2410-9908.2018 .6 .237-248$

\title{
A STUDY OF GAS PIPELINE EMERGENCY FAILURE
}

\author{
D. V. Novgorodov ${ }^{\text {a)* }}$, V. G. Rybalko ${ }^{\text {b) }}$, A. S. Shleenkov ${ }^{\text {()) }}$, and A. Yu. Surkov ${ }^{\text {d) }}$ \\ M. N. Miheev Institute of Metal Physics, Ural Branch of the Russian Academy of Sciences, \\ 18 S. Kovalevskoy St., Ekaterinburg, Russian Federation
}

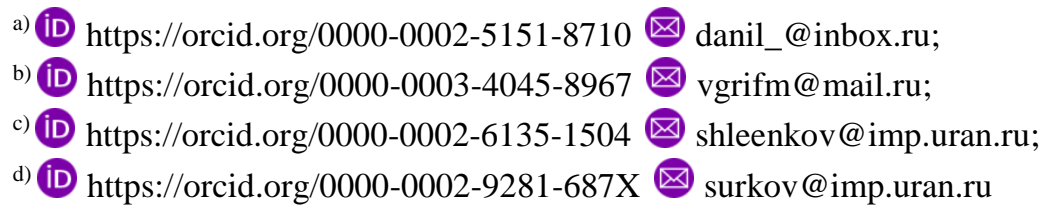

\author{
*Corresponding author. E-mail: danil_@inbox.ru \\ Address for correspondence: ul. S. Kovalevskoy, 18, Ekaterinburg, 620990, Russian Federation
}

The paper presents the results of studying the causes of emergency failure of a gas pipeline with a diameter of $377 \mathrm{~mm}$ and a wall thickness of $6 \mathrm{~mm}$ (spiral-welded pipe). The gas pipeline has been operated for more than 35 years. In the process of the study, metal-fractographic analysis and mechanical tests were carried out. As a result, it has been established that the pipe material corresponds to the design solutions and that the overload is not associated with the growth of internal pressure. The reason for the force overload in the fracture zone is the ground instability caused by seasonal temperature fluctuations. The analysis of the causes of emergency failure makes it possible to improve the reliability of the pipeline through measures aimed at reducing off-design loads.

Keywords: gas pipeline, emergency failure, testing, research methods, fracture, strength calculation, force overload.

\section{Acknowledgment}

The work was performed within the state assignment from FASO Russia on the subject of Diagnostics, No. AAAA-A18-118020690196-3.

\section{References}

1. Nikolaeva M.V., Atlasov R.A., Filippova M.D. Analysis of the causes of emergency situations at gas pipelines in permafrost. Vestnik of North-Eastern Federal University: Earth Sciences Series, 2017, vol. 4 (08), pp. 47-53. (In Russian).

2. Revazov A.M. Analysis of emergency and accidental situations at the main gas pipeline facilities, and the measures to prevent their occurrence and reduce the consequences. Upravlenie Kachestvom v Neftegazovom Komplekse, 2010, vol. 1, pp. 68-70. (In Russian).

3. Bolshakov A.M., Golikov N.I., Syromyatnikova A.S., Alekseev A.A., Tikhonov R.P. Fracture and Damage of Oil and Gas Industry Constructions in Long-Term Operation. Gaz. Promysh., 2007, vol. 7, pp. 89-91. (In Russian).

4. Chuhareva N.V., Mironov S.A., Tikhonova T.V. Analysis of accident causes in pipeline operation in the Far North during the period from 2000 to 2010. Elektronnyi nauchnyi zhurnal "Neftegazovoe Delo”, 2011, no. 3, pp. 231-243. Available at: http://www.ogbus.ru/authors/Chuhareva/Chuhareva_1.pdf 5. $\quad$ Sageeva Z.Z., Khayrullin R.Z. Analysis of emergency situations on the linear part of gas mains. Science Almanac, 2017 no. 4-3 (30). (In Russian). 
6. Gostinin I.A., Viryasov A.N., Semenova M.A. The analysis of emergencies on linear part of the main gas pipelines. Inzhenernyi Vestnik Dona., 2013, no. 2. (In Russian). Available at: ivdon.ru/ru/magazine/archive/n2y2013/1618

7. Savonin S.V., Moskalenko A.V., Tyunder A.V., Knyazev S.E., Arsenteva Z.A. Analysis of the major causes of failures that have occurred on main gas pipelines. Neft $i$ Gaz Sibiri, 2015, vol. 4 (21), pp. 112-121. (In Russian).

8. Daunis M.A., Timofeev B.T. Some features of assessment of low-cycle fatigue of welded joints in power engineering. Scientific and Technical Journal "Problems of Materials Science", 2007, vol. 3 (51), pp. 127-140. (In Russian).

9. Berg V.I., Chekardovskiy M.N., Yakubovskaya S.V., Toropov V.S. Influence of heterogeneity of mechanical properties of various zones of the welded butt joints work connections in elastic-plastic deformation stage. Modern Problems of Science and Education, 2015, vol. 2 (part 3). (In Russian). Available at: https://science-education.ru/en/article/view?id=23518

10. Akulov A.I., Alekhin V.P., Ermakov S.I., Polevoy G.V., Rybachuk A.M., Chernyshov G.G., Yakushin B.F. Tekhnologiya i Oborudovanie Svarki Plavleniem i Termicheskoy Rezki [Technology and Equipment for Fusion Welding and Thermal Cutting, A.I. Akulov, ed.]. Moscow, Mashinostroenie Publ., 2003, 560 p.

11. SNiP 2.05.06-85. Magistralnye truboprovody [Trunk Pipelines]. Moscow, Stroyizdat Publ., 1997, 59 p. (In Russian).

12. SP 36.13330.2012: Svod pravil. Magistralnye truboprovody [Code of Practice. Trunk Pipelines]. Moscow, Gosstroy Publ., 2012, 97 p. (In Russian). 
Подана в журнал: 01.10.2018

УДК 620.179.143

DOI: $10.17804 / 2410-9908.2018 .6 .237-248$

\title{
ИССЛЕДОВАНИЕ АВАРИЙНОГО РАЗРУШЕНИЯ ГАЗОПРОВОДА
}

\author{
Д. В. Новгородов ${ }^{\text {a)* }}$, В. Г. Рыбалко ${ }^{\text {б) }}$, А. С. Шлеенков ${ }^{\text {в) }}$, А. Ю. Сурков ${ }^{\text {г) }}$ \\ Институт физики металлов им. М.Н. Михеева УрО РАН, \\ ул. С. Ковалевской 18, г. Екатеринбург, Российская Федерация

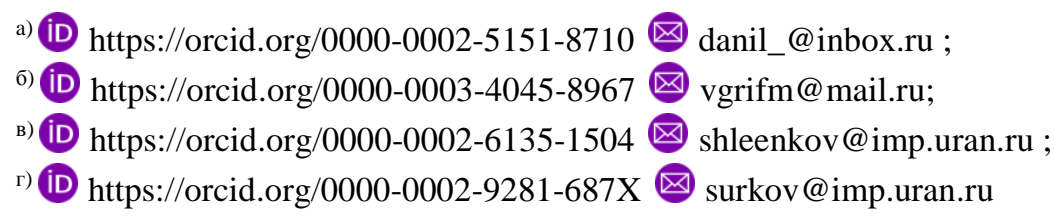 \\ *Ответственный автор. E-mail: danil_@inbox.ru \\ Адрес для переписки: ул. С. Ковалевской, 18, 620990, Екатеринбург, Российская Федерация
}

\begin{abstract}
В представленной статье приведены результаты исследования причин аварийного разрушения газопровода диаметром 377 мм с толщиной стенки 6 мм, труба спиральношовная. Газопровод эксплуатируется более 35 лет. В процессе исследования проводился металлофрактографический анализ и механические испытания. В результате установлено, что материал трубы соответствует проектным решениям, перегрузка не связана с ростом внутреннего давления. Причиной силовой перегрузки в зоне разрушения является грунтовая неустойчивость, вызванная сезонным колебанием температур. Анализ причин аварийного разрушения позволяет повысить надежность работы трубопровода с помощью проведения мероприятий, направленных на снижение непроектных нагрузок.
\end{abstract}

Ключевые слова: газопровод, аварийные разрушение, испытание, методы исследование, излом, расчет на прочность, силовая перегрузка.

\section{1. Введение}

Наибольшая часть газотранспортной системы России была построена в 70-80 гг. прошлого века. Строились трубопроводы в основном большого диаметра, газопроводыотводы строились одновременно с ними и продолжают строиться сегодня, расширяя перечень населенных пунктов, которые становятся газифицированы. Основная часть газопроводов выполнена схеме подземной прокладки и имеет схожие условия работы в одном регионе. И если анализ причин аварийного разрушения газопроводов 1000-1400 диаметра довольно подробно описан [1-4], то о причинах аварий на трубопроводах малого диаметра количество данных ограниченно. В статье мы проведем исследование о причинах аварийного разрушения, которое произошло на газопроводе-отводе выполненного из спиральношовной трубы наружным диаметром 377 и толщиной стенки 6 мм. Сведения о реальных причинах аварии позволят газотранспортным предприятиям учитывать условия эксплуатации и возможные риски при планировании диагностических работ и предупредительных мероприятий, для снижения вероятностей аналогичных аварий. Для исследования эксплуатирующей организацией были предоставлены фрагменты с места аварии, в том числе: четыре со следами разрушения (деформации) (рис. 1) и два с неповрежденного места для оценки механических свойств. Оценка механических свойств проводилась на стандартных образцах (рис. 2). I типа номер 21 [ГОСТ 1497-84].

Осмотр разрушенных участков установил, что магистральная трещина началась с основного металла тела трубы, рост происходил по телу трубы и границам сварного шва. 
При визуальном осмотре внешней и внутренней стороны фрагментов, а также при их сканировании с применением вихретокового дефектоскопа ВК-1 было выявлено, что поверхность не содержит коррозийных повреждений и трещин.

На внешней поверхности трубы присутствует протяженная деформационная полоса (след от ролика), которая представляет собой уступ с параметрами глубины - 0,5 мм и ширины - 5 мм рис. 3 a. Данный след располагается вдоль сварочного шва на расстоянии 15 мм от границы сплавления. Следует отметить, что магистральная трещина развивалась независимо со следом от ролика. Именно поэтому нельзя сказать, что данное механическое повреждение является главным фактором разрушения.
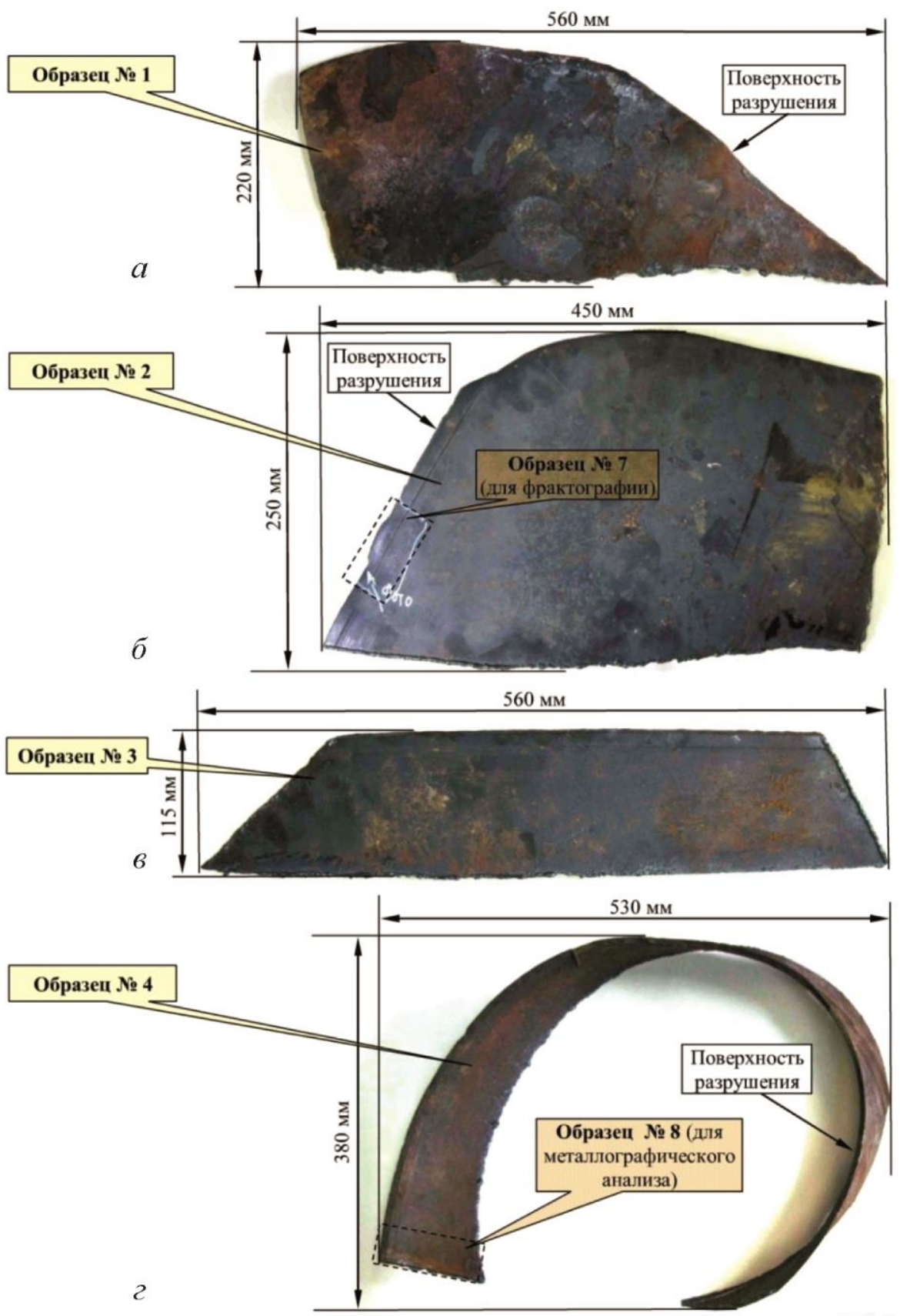

Рис. 1. Фрагменты (образцы) аварийной трубы (377×6 мм), представленные для лабораторных исследований 


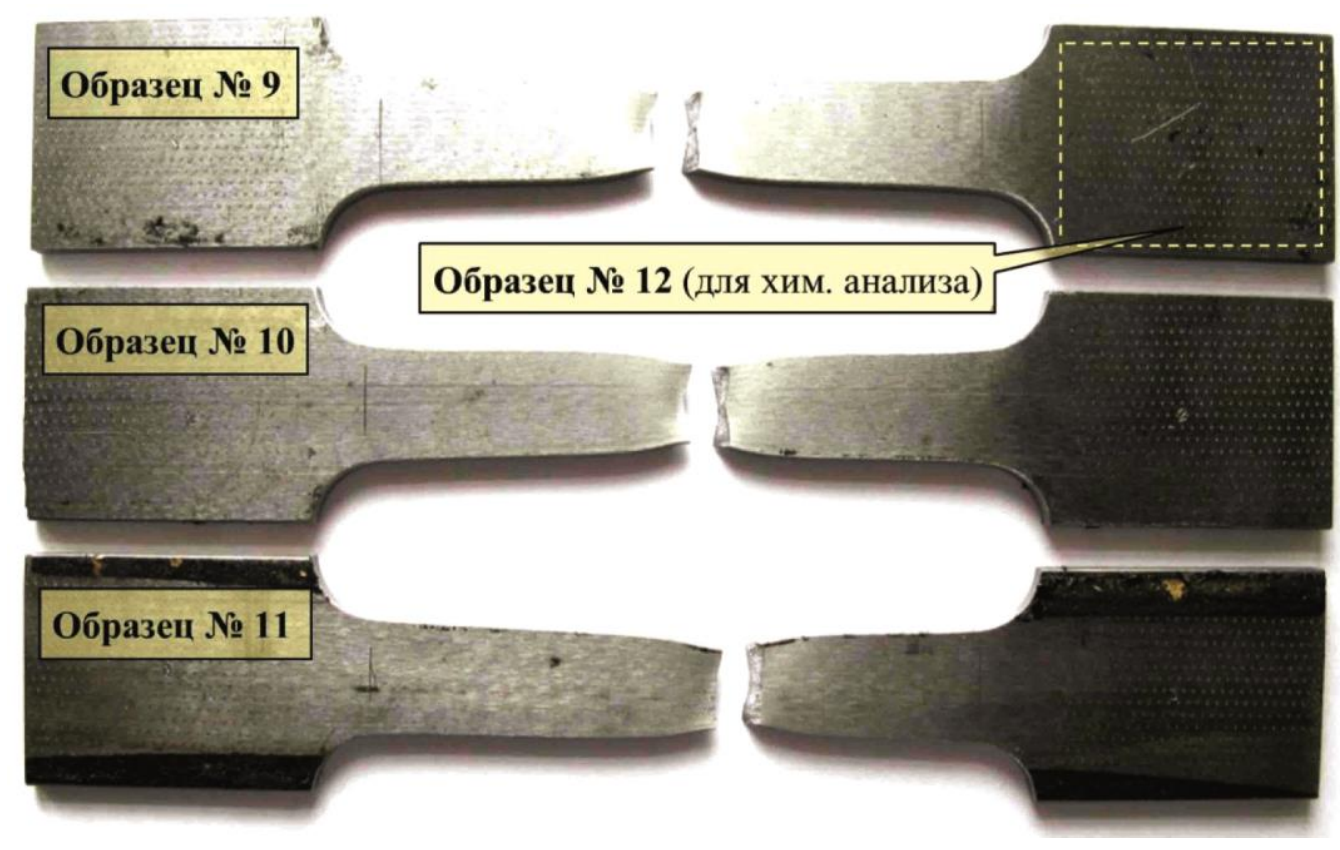

$a$
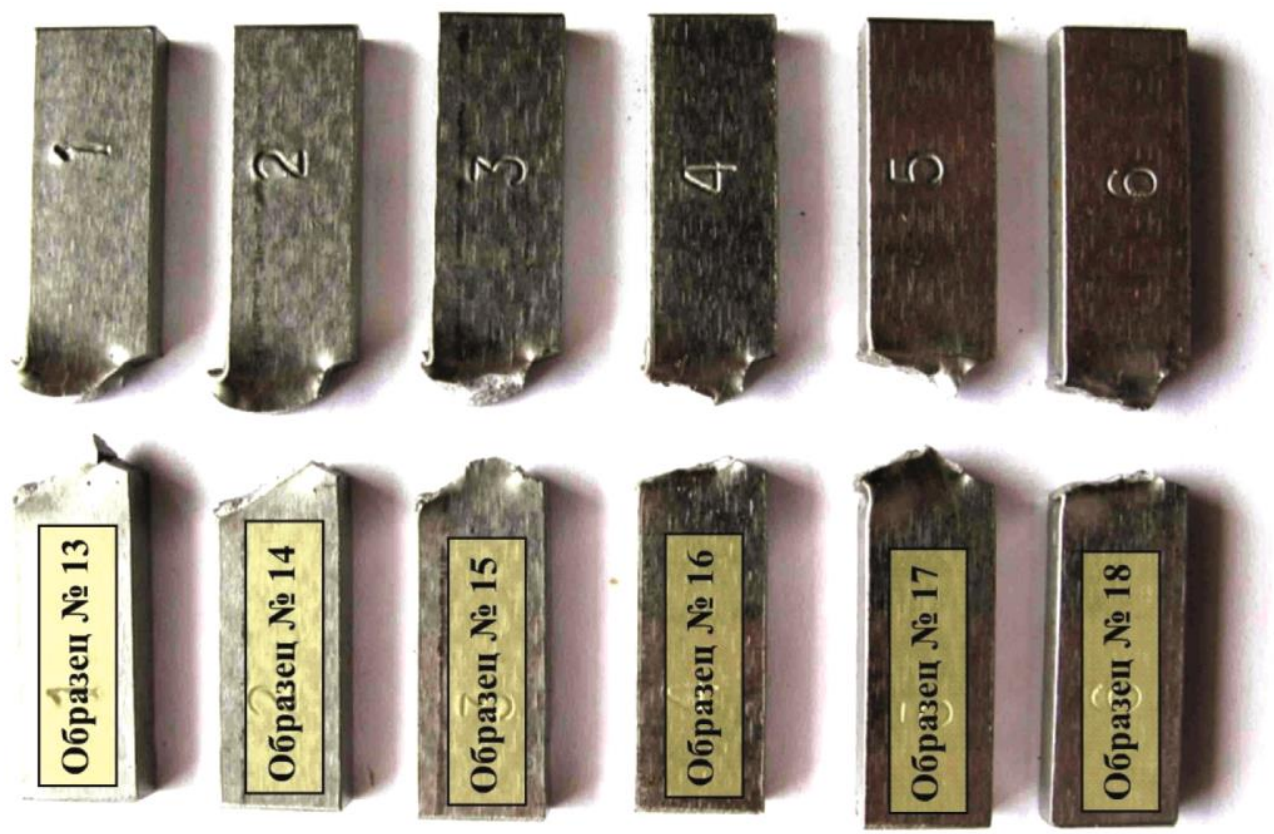

$\sigma$

Рис. 2. Общий вид образцов для испытаний: $a$ - образцы для испытаний на растяжение; $\sigma$ - образцы для испытаний на ударный изгиб.

Глубокий след от ролика (0,5 мм) свидетельствует о том, что при изготовлении применялся избыточно силовой метод для подгибания кромки трубы, либо трубопрокатное оборудование было неисправно. Это привело к тому, что в шве и околошовной зоне возникли высокие остаточные напряжения. 


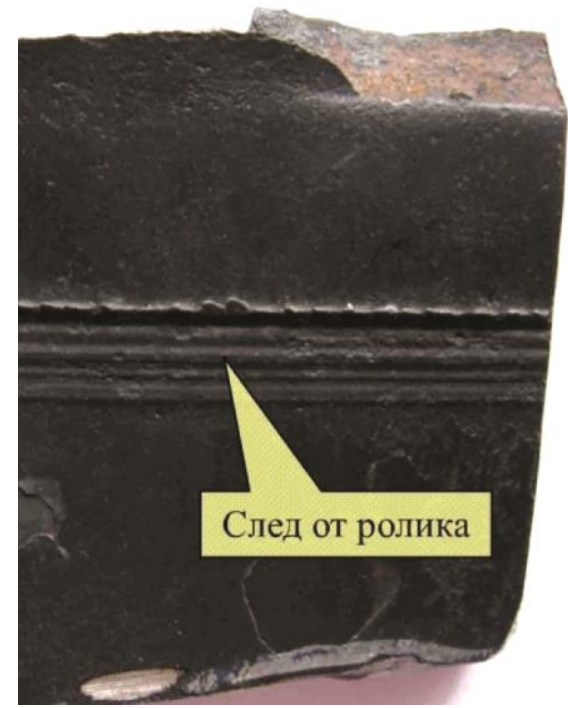

$a$

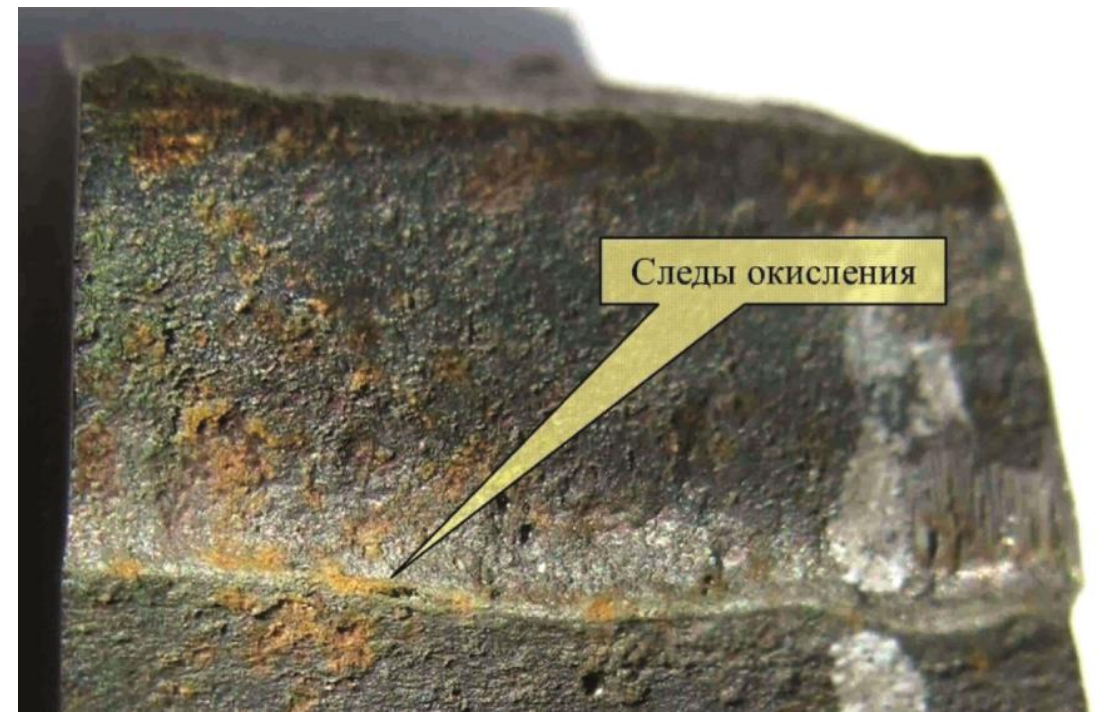

6

Рис. 3. Дефекты на поверхности трубы и сварном соединении: $a$ - след от ролика глубиной 0,5 мм; $\sigma$ - следы окисления шва

В процессе изучения было обнаружено наличие следов окисления на наружной поверхности сварного соединения. Следы представлены в виде коротких участков, которые имеют длину 2-3 мм и глубину 0,3-0,5 мм (рис. 3 б). Это свидетельствует о сниженной прочности сварного соединения. Можно предположить, что причиной разрушения магистральной трубы могла послужить перегрузка относительно проектного нормативного уровня, так как не были выявлены следы коррозии и механических повреждений. При исследовании разрушенной поверхности было выявлено, что она ориентирована под углом 45 град. к поверхности трубы, шероховатая и вязкая по типу среза - следствие перегрузки. В этом случае сам факт разрушения определяется величиной перегрузки, а разрушение - наличием ослабленного сечения. Принято считать, что прочность металла в сварных соединениях (зона шва) может быть несколько меньше, чем прочность основного металла, и варьироваться в пределах 20-25 \%. [8] Если не обнаружено других дефектов, необходимо определять положение места начала разрушения по границе сварного шва $[9,10]$.

Исследование разрушенной поверхности выявило короткий участок излома, длина которого составляет 45 мм. Данный участок отличается от других участков пространственной ориентацией на $90^{\circ}$ и фактурой излома. При этом фактура излома представлена продольной слоистостью при вязком разрушении (рис. 4). Стоит отметить, что на этом участке трубы минимальной толщиной стенки является показатель 5 мм, при этом на соседних участках 5,5 мм. Такие показатели могут свидетельствовать о большей степени пластической деформации, которая предшествовала разрушению на участке очага.

В пользу предположения, что именно этот участок является очагом разрушения указывает и тот факт, что трещина, в случае ее роста с другого участка, не могла (из соображений минимума энергетических затрат на распространение) дважды изменить направление(ориентацию) на коротком участке длиной 45 мм. Для того чтобы объяснить природу возникновения излома на участке можно предположить, что именно он является местом начала разрушения и именно от него образовалась трещина первоначально при пластическом деформировании по толщине стенки, после чего распространилась в другие стороны от начала в продольном направлении. Объяснить строение излома на данном участке можно только предположив, что это есть очаг разрушения, от которого трещина образовалась вначале при пластическом деформировании по толщине стенки, затем распространялась в обе стороны от очага в продольном направлении. 


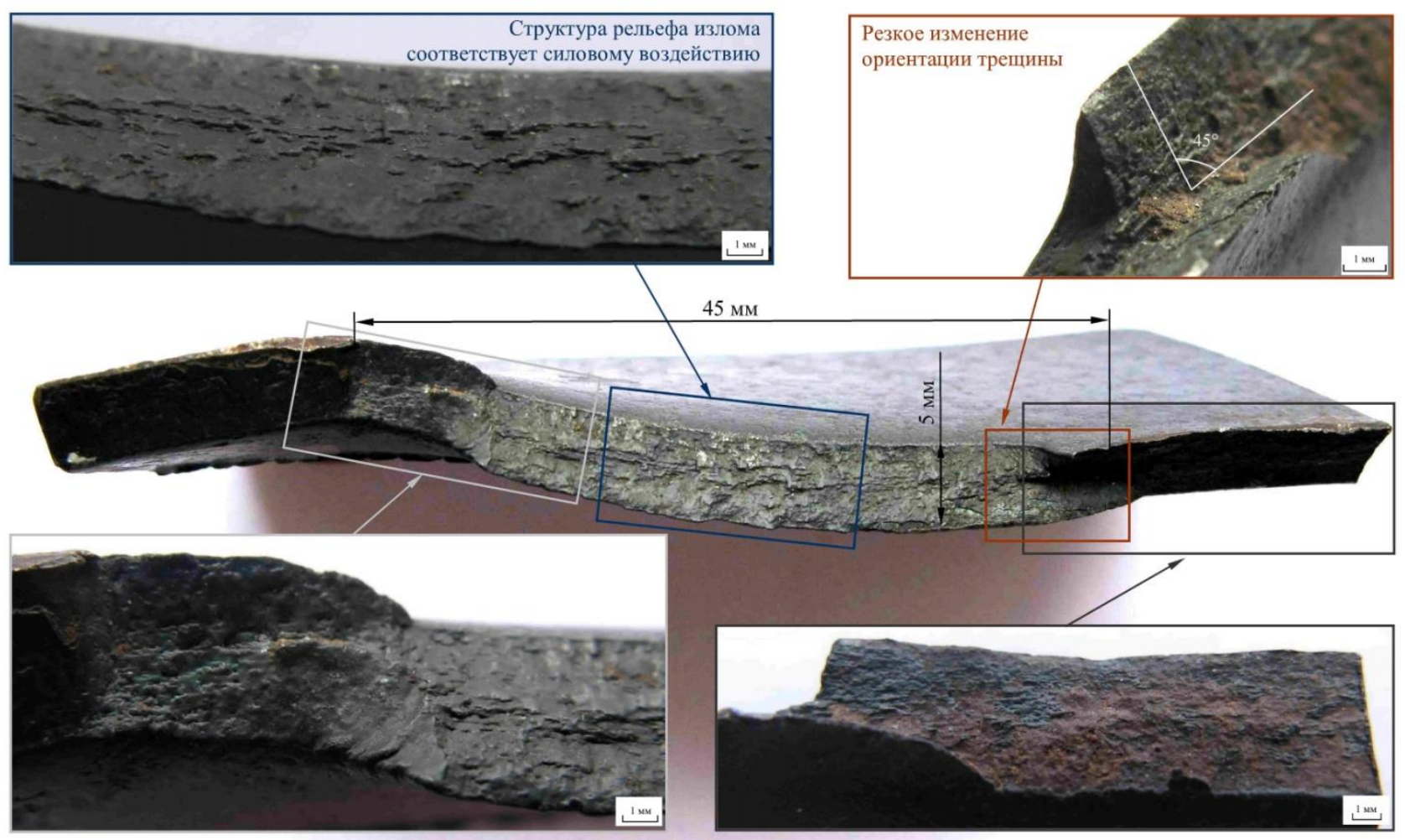

Рис. 4. Общий вид излома стенки аварийной трубы (участок силового воздействия), образец № 7

Характеристикой, несущей способности при разрушении трубы, является предел прочности материала. При отсутствии достоверных данных о фактическом уровне действующих напряжений расчет на прочность выполняется в предположении равномерного распределения напряжений от внутреннего давления по сечению трубы. Максимальные напряжения от внутреннего давления $P$ кольцевые, поэтому разрушение трубы с диаметром $D$ и толщиной стенки $t$ произойдет разрывом вдоль осевой линии. Разрушение наступит, когда кольцевые напряжения $\sigma_{\kappa}$ достигнут по значению величины предела прочности $\sigma_{b}$ в нетто сечении стенки трубы:

$$
\sigma_{k}=\frac{P(D-2 t)}{2 t}=\sigma_{b}
$$

При наличии продольной трещины глубиной $h$ и длиной $L$ условие прочности можно переписать в виде зависимости критической глубины трещины $h$ от длины дефекта и давления эксплуатации, при достижении которой произойдет разрыв стенки трубы по толщине:

$$
h=t \sqrt{\frac{D}{L}\left(1-\frac{(D-2 t)}{2 t \sigma_{b}}\right)} .
$$

На рис. 5 представлен график зависимости между длиной и глубиной трещины, при достижении которых для трубы $377 \times 6$ мм при давлении 5,4 МПа произойдет разрыв по толщине стенки. 
Видно, что при минимальных значениях длины дефекта 150-200 мм критическая трещина для разрыва по толщине стенки должна быть практически сквозной. Поскольку дефекты указанных размеров на представленных фрагментах (образцах) не обнаружены, можно полагать, что причина разрушения прямо не связана с уровнем внутритрубного давления. Следовательно, кроме внутреннего давления были и другие воздействия. В нормативной документации $[11,12]$ при расчете критического напряжения необходимо кроме внутреннего давления учитывать также изгибные напряжения и напряжения от температурных перепадов. Учитывая срок наработки газопровода более трех десятков лет, можно достаточно достоверно предположить о малозначительности температурного перепада при расчете напряжений. Таким образом, остается влияние изгибных напряжений, которые суммируясь с остальными нагрузками, достигли значения предела прочности стали и вызвали разрушение. По нашему мнению, наиболее вероятной причиной возникновения силовой перегрузки и возникновения значительных изменений может быть грунтовая неустойчивость в виде пучения грунта от сезонных перепадов температуры.

Для оценки соответствия материала трубы нормативным требованиям и оценки механических свойств проводились стандартные механические испытания.

Исследование качества материала аварийной трубы показало, что материал трубы соответствует элементному составу качественной углеродистой стали (Сталь 20). Сравнение полученных результатов с данными сертификата и ГОСТ 1050-74 приведены в табл. 1. Для определения элементного состава (марки стали) был применен спектрометр «SPECTRO TEST».

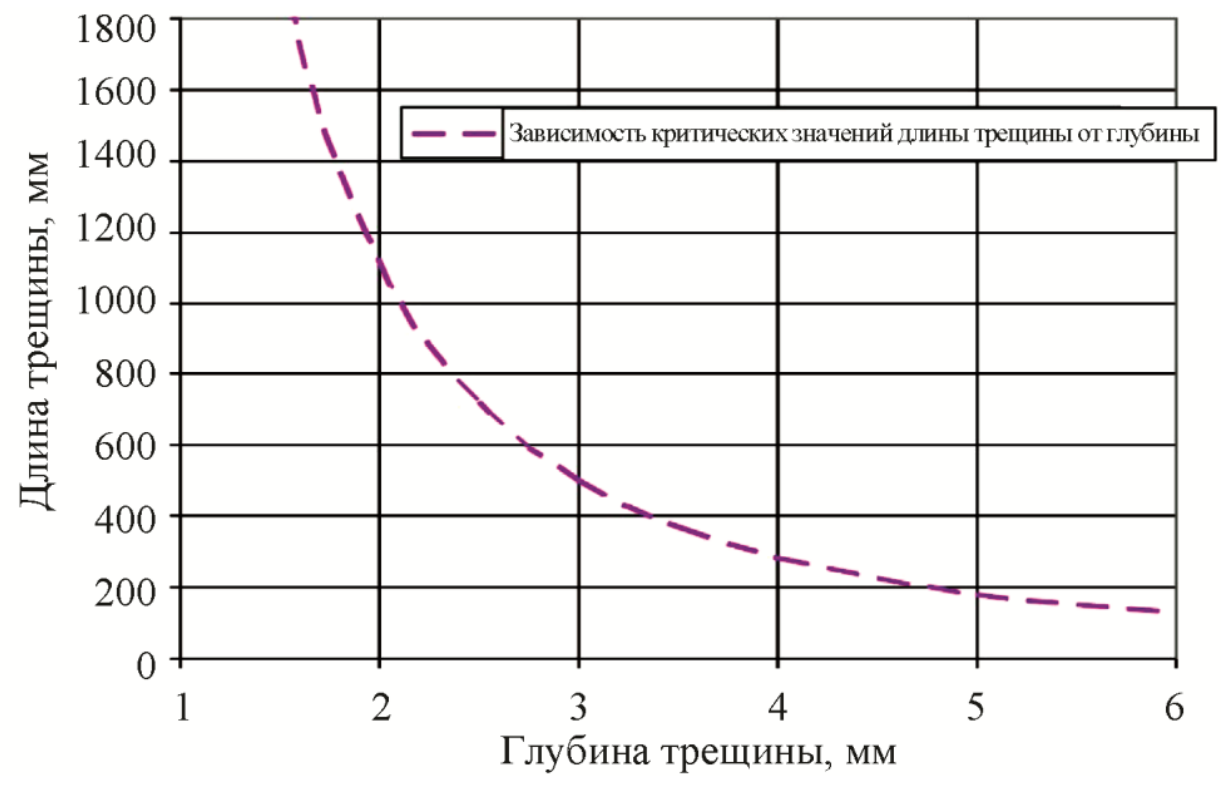

Рис. 5. Критические размеры трещин (труба 377×6 мм, сталь 20, давление 5,4 МПа)

Металлографический анализ материала аварийной трубы, проведенный на образце № 8, вырезанном в зоне ее разрушения, показал, что структура основного металла трубы феррито-перлитная смесь (рис. 6 a), соответствует структуре стали 20 в отожженном состоянии. Структура металла ОШЗ (околошовной зоны) (рис. 6 в) и металла сварных швов (рис. 6 б, г) типична для сварного соединения. Дефектов в плоскости исследованного шлифа не выявлено. При этом наблюдается повышенная неоднородность по размеру ферритных зерен и дисперсности выделений перлита, что является следствием температурного воздействия (горения трубы). Поверхность разрушения проходит через ОШЗ от границы сплавления нижнего сварного шва к наружной поверхности трубы на расстоянии 3 мм от верхней границы сплавления (под углом $45^{\circ}$ ). 
Таблица 1 - Химический состав материала трубы

\begin{tabular}{|c|c|c|c|c|c|c|c|c|}
\hline \multirow{2}{*}{$\begin{array}{c}\text { Место отбора } \\
\text { образцов }\end{array}$} & \multicolumn{9}{|c|}{ Химические элементы, \% } \\
\cline { 2 - 9 } & $\mathrm{C}$ & $\mathrm{Si}$ & $\mathrm{Mn}$ & $\mathrm{S}$ & $\mathrm{P}$ & $\mathrm{Cu}$ & $\mathrm{Cr}$ & $\mathrm{Ni}$ \\
\hline $\begin{array}{c}\text { Труба } \\
\text { 377×6 мм }\end{array}$ & 0,205 & 0,198 & 0,444 & - & - & 0,105 & 0,074 & 0,068 \\
\hline $\begin{array}{c}\text { По сертифи- } \\
\text { кату № 429-1 }\end{array}$ & 0,19 & - & $\begin{array}{c}0,49- \\
0,51\end{array}$ & $\begin{array}{c}0,016- \\
0,020\end{array}$ & $\begin{array}{c}0,016- \\
0,024\end{array}$ & - & $\begin{array}{c}0,25- \\
0,30\end{array}$ & - \\
\hline $\begin{array}{c}\text { ГОСТ } \\
\text { 1050-74, } \\
\text { Сталь 20 }\end{array}$ & $0,17-$ & $0,17-$ & $0,35-$ & не более \\
0,37 & 0,65 & $\begin{array}{c}\text { не более } \\
0,035\end{array}$ & $\begin{array}{c}\text { не более } \\
0,25\end{array}$ & $\begin{array}{c}\text { не более } \\
0,25\end{array}$ & $\begin{array}{c}\text { не более } \\
0,25\end{array}$ \\
\hline
\end{tabular}
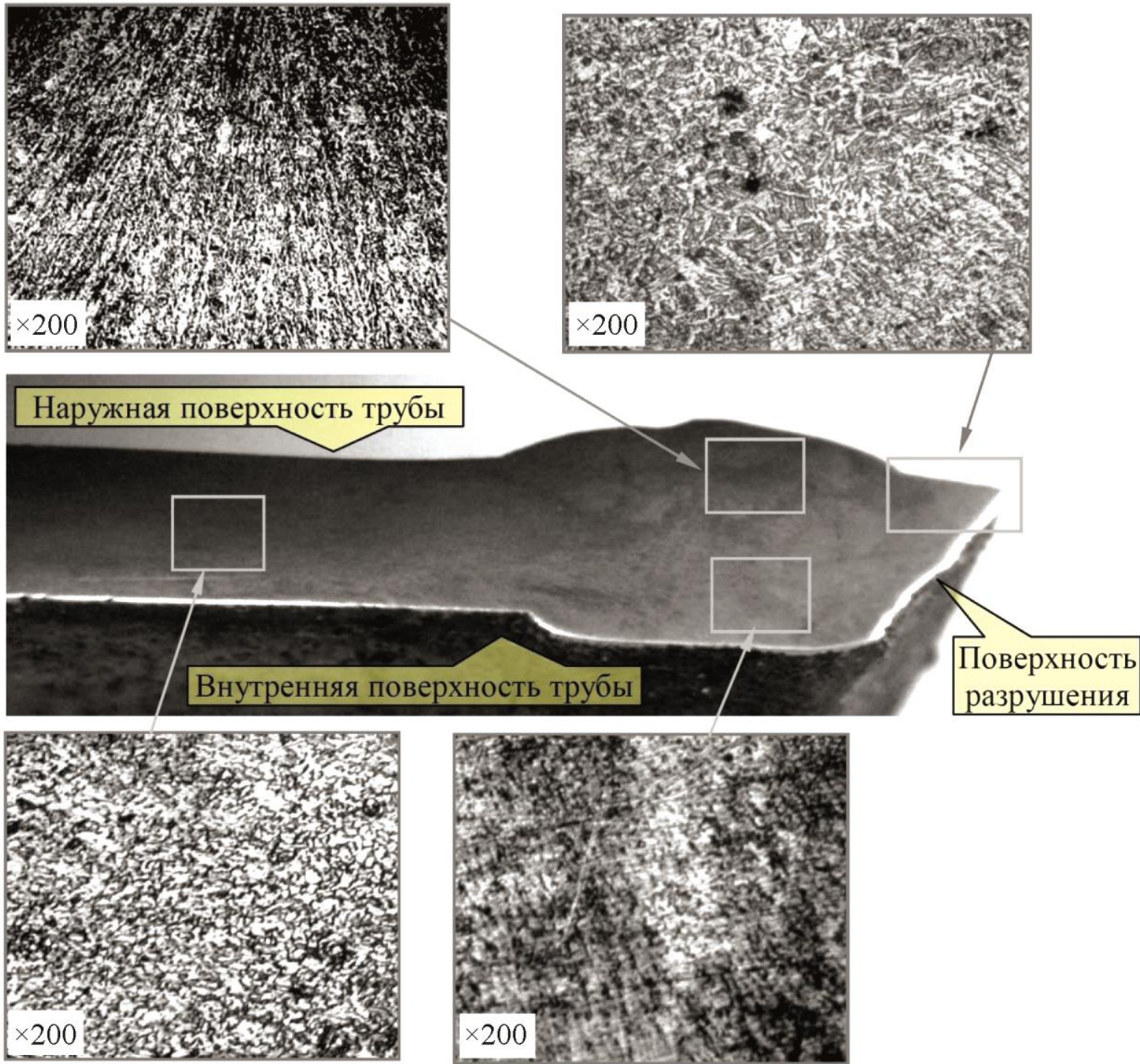

Рис. 6. Микроструктура материала трубы и сварного соединения вблизи поверхности разрушения (поперечный шлиф), ×5: $a$ - структура основного металла трубы: феррито-перлитная смесь в отожженном состоянии, $\times 50 ; 6$, г - сварной шов: $\sigma$ - верхний шов, столбчатая литая структура, $\times 50 ; 2-$ нижний шов, частично перекристаллизированная литая структура, $\times 50$; в - граница сплавления верхнего шва, $\times 50$ 
Испытания на статическое растяжение были проведены на образцах № 9, 10 и 11 изготовленных токарно-фрезерным способом (рис. 2). Порядок проведения испытаний и оценка результатов в соответствии с требованиями ГОСТ 1497-84. Средние значения параметров прочности $\left(\sigma_{\mathrm{B}}, \sigma_{0,2}\right)$ и пластичности $\left(\delta, \psi, \sigma_{0,2 / \mathrm{B}}\right)$, полученные в результате проведенных механических испытаний материала трубы на статическое растяжение в сравнении с данными ГОСТ 1050-88, СНиП 2.05.06-85 и сертификата на трубу представлены в табл. 2.

Таблица 2 - Средние значения механических параметров материала трубы

\begin{tabular}{|c|c|c|c|c|c|}
\hline $\begin{array}{c}\text { Место } \\
\text { отбора } \\
\text { образцов }\end{array}$ & $\begin{array}{c}\text { Предел } \\
\text { прочности, } \\
\text { бВ, МПа }\end{array}$ & $\begin{array}{c}\text { Предел } \\
\text { текучести, } \\
\sigma_{0,2}, \text { МПа }\end{array}$ & $\begin{array}{c}\text { Относительное } \\
\text { удлинение, } \\
\delta, \%\end{array}$ & $\begin{array}{c}\text { Относительное } \\
\text { сужение, } \\
\psi, \%\end{array}$ & $\begin{array}{c}\text { Показатель } \\
\text { пластичности } \\
\text { материала, } \\
\sigma_{0,2}, / \sigma_{\mathrm{B}} \\
\end{array}$ \\
\hline $\begin{array}{c}\text { Стенка трубы } \\
377 \times 6 \text { мм }\end{array}$ & 409 & 295 & 28,9 & 59,4 & 0,72 \\
\hline $\begin{array}{c}\text { По данным } \\
\text { сертификата } \\
\text { № 429-1 }\end{array}$ & $430-460$ & $280-300$ & $33,8-35,4$ & - & - \\
\hline $\begin{array}{c}\text { ГОСТ } \\
1050-88^{*} \\
\end{array}$ & $\begin{array}{c}\text { не менее } \\
410 \\
\end{array}$ & - & $\begin{array}{c}\text { не менее } \\
25\end{array}$ & $\begin{array}{l}\text { не менее } \\
55\end{array}$ & - \\
\hline $\begin{array}{c}\text { СНиП } \\
2.05 .06-85\end{array}$ & - & - & не менее 20 & - & не более 75 \\
\hline
\end{tabular}

*Сталь 20 горячекатаная и нормализованная

Из табл. 2 следует, что результаты проведенных испытаний на статическое растяжение показывают соответствие механических свойств $\left(\sigma_{\mathrm{B}}, \sigma_{0,2}, \delta, \psi, \sigma_{0,2} / \sigma_{\mathrm{B}}\right)$ требованиям, предъявляемым к трубам из стали 20 по ГОСТ 1050-88, класса прочности К-42.

Испытания на ударный изгиб были проведены на образцах № 13, 14, 15, 16, 17 и 18 изготовленных токарно-фрезерным способом. Средние значения параметров ударной вязкости (KCU) полученные в результате проведенных испытаний материала трубы в сравнении с данными ГОСТ 20295-85 и СНиП 2.05.06-85 представлены в таблице 3. Из табл. 3 следует, что результаты проведенных испытаний на ударный изгиб показывают снижение ударной вязкости материала аварийной трубы в сравнении с данными ГОСТ 20295-85 и СНиП 2.05.06-85.

Таблица 3 - Результаты механических испытаний на ударный изгиб

\begin{tabular}{|c|c|c|c|}
\hline \multirow{2}{*}{$\begin{array}{c}\text { № } \\
\text { образца }\end{array}$} & \multirow{2}{*}{$\begin{array}{c}\text { Температура } \\
\text { испытания, }{ }^{\circ} \mathrm{C}\end{array}$} & \multicolumn{2}{|c|}{ 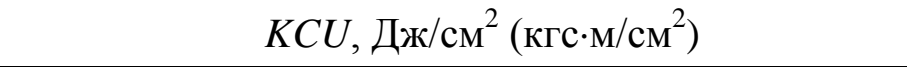 } \\
\hline & & Значения по испытаниям & Среднее значение \\
\hline 13 & \multirow{3}{*}{20} & 33,2 & \multirow{3}{*}{31,1} \\
\hline 14 & & 31,1 & \\
\hline 15 & & 29,7 & \\
\hline 16 & \multirow{3}{*}{-20} & 22,1 & \multirow{3}{*}{23,2} \\
\hline 17 & & 28,4 & \\
\hline 18 & & 19,2 & \\
\hline $\begin{array}{c}\text { ГОСТ } \\
20295-85\end{array}$ & -40 & - & $29,4(3)$ \\
\hline $\begin{array}{c}\text { СНиП } \\
2.05 .06-85\end{array}$ & -40 & - & $29,4(3)$ \\
\hline
\end{tabular}


Таким образом, результаты исследования фрагментов разрушенной трубы подтвердили, что наиболее вероятной причиной аварии трубопровода была силовая перегрузка, вызвавшая образование сквозной трещины (очага) длиной 45 мм при вязком разрушении по границе спирального шва и дальнейшее распространение трещины срезом в обе стороны от очага. Приведенный ход развития разрушения наиболее достоверен при описании характерных особенностей исследованных фрагментов трубопровода.

После возникновения силовой перегрузки, которая послужила причиной образования магистральной трещины, рост дефекта не происходил до момента потери трубой несущей способности из-за повышенных напряжений, за которым через короткое время последовал разрыв газопровода. Безопасная эксплуатация трубы с допустимыми дефектами, таким образом, требует также контроля напряженно-деформированного состояния трубопровода. Для снижения вероятности возникновения аварийных ситуаций, аналогичных рассмотренным, необходимо наблюдение за стабильностью пространственного положения трубопроводов на сложных участках с помощью геопозиционирования, проведения внутритрубной диагностики или установки стационарных систем контроля напряженно-деформированного состояния, что даст возможность своевременно принимать меры по снижению непроектных нагрузок.

\section{Благодарность}

Работа выполнена в рамках государственного задания ФАНО России (тема «Диагностика»), № AAAA-A18-118020690196-3.

\section{Литература}

1. Николаева М. В., Атласов Р. А., Филиппова М. Д. Анализ причин аварийных ситуаций газопроводов, проложенных в многолетнемерзлых грунтах // Вестник СВФУ. - Серия «Науки о земле». - 2017. - № 4 (08) - С. 47-53.

2. Ревазов А. М. Анализ чрезвычайных и аварийных ситуаций на объектах магистрального газопроводного транспорта и меры по предупреждению их возникновения и снижению последствий // Управление качеством в нефтегазовом комплексе. - 2010. - № 1. C. $68-70$.

3. Разрушения и повреждения при длительной эксплуатации объектов нефтяной и газовой промышленности / А. М. Большаков, Н. И. Голиков, А. С. Сыромятникова, А. А. Алексеев, Р. П. Тихонов // Газовая промышленность. - 2007. - № 7. - С. 89-91.

4. Чухарева Н. В., Тихонова Т. В., Миронов С. А. Анализ причин аварийных ситуаций при эксплуатации магистральных трубопроводов в условиях Крайнего Севера в период с 2000 по 2010 год // Электронный научный журнал «Нефтегазовое дело». - 2011. - № 3. C. 231-243. - URL: http://www.ogbus.ru/authors/Chuhareva/Chuhareva_1.pdf

5. Сагеева 3. 3., Хайруллин Р. 3. Анализ аварийных ситуаций на линейной части магистральных газопроводов // Научный альманах. - 2017. - № 4-3 (30). - С. 158-161.

6. Гостинин И. А., Вирясов А. Н., Семенова М. А. Анализ аварийных ситуаций на линейной части магистральных газопроводов // Электронный научный журнал «Инженерный вестник Дона». - 2013. - Т. 25, № 2 (25). - URL: ivdon.ru/ru/magazine/archive/n2y2013/1618

7. Анализ основных причин аварий, произошедших на магистральных газопроводах / С. В. Савонин, А. В. Москаленко, А. В. Тюндер, С. Е. Князев, 3. А. Арсентьева // Нефть и Газ Сибири. - 2015. - № 4 (21). - С. 112-121.

8. Тимофеев Б. Т., Даунис М. А. Некоторые особенности оценки малоцикловой усталости сварных соединений в энергетике // Вопросы материаловедения. - 2007. - № 3 (51). - С. 127-140.

9. Влияние неоднородности механических свойств различных зон сварного стыкового соединения на работу соединения в упругопластической стадии деформации / В. И. Берг, М. Н. Чекардовский, С. В. Якубовская, В. С. Торопов // Современные проблемы науки 
и образования. - 2015. - № 2 (часть 3). - URL: http://science-education.ru/ru/article/view?id=23518 (дата обращения: 26.12.2018).

10. Акулов А. И. Технология и оборудование сварки плавлением. - М. : Машиностроение, 2003. - $560 \mathrm{c}$.

11. СНиП 2.05.06-85. Магистральные трубопроводы. - М. : Стройиздат, 1997. - 59 с.

12. СП 36.13330.2012. Свод правил. Магистральные трубопроводы. Актуализированная редакция СНиП 2.05.06-85. - М. : Госстрой, 2012. - 97 с. 